\title{
РОЛЬ ТИРЕОТРОПНОГО ГОРМОНА В РАЗВИТИИ ПОРАЖЕНИЯ МЫШЦ У БОЛЬНЫХ КОМПЕНСИРОВАННЫМ ГИПОТИРЕОЗОМ НА ФОНЕ СТАТИНОТЕРАПИИ
}

\author{
Луговая Л.А.
}

\author{
ФГБОУ ВО «ПИМУ» Минздрава России
}

Гипотиреоз - патология, приводящая к увеличению сердечно-сосудистого риска, что требует назначения статинов. Однако статины не лишены побочных эффектов. Частота симптомов поражения мышц, связанных с приемом статинов (СПМ-СПС) достигает 29\%. Немногочисленные данные о повышении риска СПМ-СПС при наличии гипотиреоза в 1,7 раз актуализируют изучение риска СПМ-СПС у данной группы пациентов.

ЦЕЛЬ: оценить вероятность развития мышечного поражения у пациентов с компенсированным гипотиреозом на фоне лечения статинов.

ЗАДАЧИ: сравнить клинико-лабораторную картину поражения мышц у больных в зависимости от наличия гипотиреоза и/или статинотерапии, определить роль уровня тиреотропного гормона (ТТГ), рассчитать степень риска развития СПМ-СПС у пациентов при наличии гипотиреоза.

МАТЕРИАЛЫ И МЕТОДЫ: поперечно обследовано 120 пациентов, поделенных на 3 группы в соответствии с наличием гипотиреоза и/или статинов (1 группа - «гипотиреоз+статины», 2 - «статины», 3 - «гипотиреоз»). Проводился осмотр пациентов, исследование ТТГ, определение уровней креатинфосфокиназы (КФК), лактатдегидрогеназы (ЛДГ) и миоглобина крови, а также генотипирование по гену SLCO1B1*5(c.521T>C).

PЕЗУЛЬТАТЫ: группы не различались по возрасту ( $>>0,05)$. Пациенты с гипотиреозом были медикаментозно компенсированы (p>0,05). Группы 1 и 2 сопоставимы по структуре и длительности статинотерапии (р>0,05). Анализ клинико-лабораторных параметров показал, что в группе «гипотиреоз+статины» чаще регистрировалась мышечная боль (67,5\%, 27,5\% и 32,5\% пациентов 1, 2 и 3 групп соответственно;

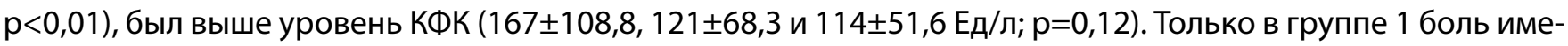
ла прямую связь с уровнем КФК $(R=0,45, p=0,004)$ и ЛДГ $(R=0,44, p=0,005)$, что указывает на повреждение миоцитов. Боль имела прямую связь с длительностью статинотерапии $(R=0,035, p=0,026)$ и с наличием C-аллеля SLCO1B1*5, повышающего риск СПМ-СПС, что указывает на вклад статинов в генез боли у пациентов с гипотиреозом. У всех пациентов с гипотиреозом была отмечена связь ТТГ с болью $(R=0,25, \mathrm{p}=0,03)$ и уровнем KФК (R=0,25, p=0,028). Для определения точки отсечения значений ТTГ, повышающих вероятность возникновения болей, ассоциированных с подъемом КФК, был проведен ROC-анализ. В 1 группе пороговое значение не определялось ( $p=0,35)$. В 3 группе точка отсечения ТTГ составила 2,86 мЕд/л (AUC $0,777, p<0,001)$. Дальнейший анализ показал, что в группе «гипотиреоз+статины» при значениях ТТГ выше или ниже порогового не различались частота жалоб на мышечную боль и уровни ферментов (p>0,05). В группе «гипотиреоз», у пациентов со значениями ТТГ<2,86 мЕд/л реже определялись жалобы на боль, чем у пациентов с ТТГ >2,86 мЕд/л (17 и 53\%; $p=0,02)$, отмечались меньшие значения ЛДГ ( $p=0,03)$ и миоглобина крови ( $p=0,03)$. При уровне ТТГ $<2,86$ мЕд/л у пациентов «гипотиреоз+статины» чаще отмечались мышечная боль и высокие значения КФК, чем у пациентов «гипотиреоз», что подчеркивает влияние статинов. По совокупности ряда параметров поражения мышц было установлено, что компенсированный гипотиреоз увеличивает риск СПМ-СПС в 2,7 раз.

ВЫВоды: назначение статинов пациентам с компенсированным гипотиреозом требует тщательного мониторинга состояния мышечной ткани, в том числе контроль уровня КФК до назначения статинов и в первые полгода статинотерапии. 